\title{
Jean-Michel Devésa, Jacques Chessex ou comment s'inventer au miroir de Dieu
}

\section{Riccardo Benedettini}

\section{(2) OpenEdition}

1 Journals

\section{Edizione digitale}

URL: http://journals.openedition.org/studifrancesi/4468

DOI: 10.4000/studifrancesi.4468

ISSN: 2421-5856

\section{Editore}

Rosenberg \& Sellier

\section{Edizione cartacea}

Data di pubblicazione: 1 settembre 2016

Paginazione: 363

ISSN: 0039-2944

\section{Notizia bibliografica digitale}

Riccardo Benedettini, «Jean-Michel Devésa, Jacques Chessex ou comment s'inventer au miroir de Dieu », Studi Francesi [Online], 179 (LX | II) | 2016, online dal 01 septembre 2016, consultato il 18 septembre 2020. URL : http://journals.openedition.org/studifrancesi/4468 ; DOI : https://doi.org/10.4000/ studifrancesi.4468

Questo documento è stato generato automaticamente il 18 settembre 2020.

\section{(c)}

Studi Francesi è distribuita con Licenza Creative Commons Attribuzione - Non commerciale - Non opere derivate 4.0 Internazionale. 


\title{
Jean-Michel Devésa, Jacques Chessex ou comment s'inventer au miroir de Dieu
}

\author{
Riccardo Benedettini
}

\section{NOTIZIA}

JEAN-MICHEL DEVÉSA, Jacques Chessex ou comment s'inventer au miroir de Dieu, Pessac, Presses Universitaires de Bordeaux, 2015, «Imaginaires et écritures», 164 pp.

1 Lavorare sulle opere di Jacques Chessex - poeta, romanziere e saggista della Svizzera romanda, noto e apprezzato anche al di fuori dei confini elvetici - è importante per gli studiosi di letteratura. La sua ampia produzione mette in luce i princìpi dell'arte del romanzo, un uso raffinato del verso poetico, che a partire dagli anni Duemila subisce un'influenza orientale (la saggezza buddista, in particolare Zen, che si mescola a quella cristiana), interessanti studi su autori della storia letteraria francese (ricordo le riflessioni su de Sade, Flaubert, Maupassant e varie altre figures de la métamorphose). Studiare Chessex significa interessarsi a una letteratura indivisibile dal Male, sulla linea di Bataille, nonché riflettere costantemente su Dio. Il libro di Jean-Michel Devésa propone una lecture di queste problematiche con uno sguardo rivolto all'assoluto, al divino e alla carne (della donna) da intendersi quale «porte du Ciel» (p. 27).

2 Rielaborazione di sei comunicazioni a convegni, come si legge nell'«Introduction. Penser l'autre sans s'effacer» (pp. 11-17), il volume si articola in sei capitoli («Le "Miroir noir" de Dieu», pp. 19-32; «L'Intuition de Dieu», pp. 39-50; «Métaphysique de l'ennui», pp. 59-70; «Le Mal, les monstres et l'ogre: Payerne, 1942», pp. 77-92; «Écrire sa légende ou faire la vie?», pp. 99-109; «Silence et parole», pp. 123-135), ciascuno dei quali è seguito da singolari «Notes de traverse» in cui l'A. riporta i momenti più intimi del personale avvicinamento all'opera di Chessex: segnalo solo le frequentazioni delle Archives littéraires suisses («Notes de traverse 1», pp. 33-37), i ricordi di quei 
«"passeurs" helvètes» («Notes de traverse 4», pp. 93-98: p. 95) che hanno influenzato la particolare visione di Devésa - nomi che poi ricorrono nelle conclusive «Sources bibliographiques» (pp. 157-160) -, gli intrecci tra l'universo di Chessex e quelli del romanzo di famiglia dell'A., con particolare riguardo alla figura del padre e al ruolo della Legge («Notes de traverse 6», pp. 137-146).

Devésa affronta la sua indagine inserendo Chessex all'interno di un'importante lignée di scrittori, svizzeri e francesi, definendo l'autore un credente che non disdegna il «charnel» (p. 20), perché «le corps demeure un "Temple de Dieu"» (p. 50). Giusto rilievo è dato al tema della letteratura che crea una tensione in grado di destare il piacere della lettura, al Male che permette il compimento del disegno divino (in Chessex, il peso della caduta e del peccato si rifà direttamente a Calvino), all'enfantillage (Bataille) dello scrittore, che sembra uscire dall'infanzia solo a ventidue anni (p. 69), alla morte del padre, momento su cui si edifica gran parte dell'opera. Rileggendo in particolare alcuni testi (La Confession du pasteur Burg, Portrait des Vaudois, L'Économie du ciel, Hosanna...), l'A. sottolinea più volte come «ce qui ne fait pas de doute, c'est qu'écrire, pour Chessex, c'est toujours écrire sur et à propos de Dieu» (p. 32). Lo studio coglie la dimensione del Male nel cuore degli uomini, responsabili, secondo Chessex, della perdita di purezza che oramai caratterizza il suo amato pays de Vaud. In questo senso, si svolge anche la «Conclusion. L'Écriture entre exorcisme et exercice spirituel» (pp. 147-155), in cui la retorizzazione del male nella scrittura assurge a un voto («vœu») finale: «Chessex a bien écrit pour ne pas mourir» (p. 155). 